\title{
Impact of global change on the biogeochemistry and ecology of an Arctic freshwater system
}

\author{
John E. Hobbie, Bruce J. Peterson, Neil Bettez, \\ Linda Deegan, W. John O'Brien, George W. Kling, \\ George W. Kipphut, William B. Bowden \\ \& Anne E. Hershey
}

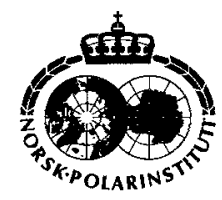

Lakes and streams in the foothills near Toolik Lake, Alaska, at $68^{\circ} \mathrm{N}$ have been studied since 1975 to predict physical, chemical and biological impacts of future global change. Experimental manipulations include whole lake and continuous stream fertilization as well as removal and addition of predators (copepods, lake trout, grayling, sculpin). Based on our evidence the following scenario is likely. Warming thaws the upper layers of permafrost and streams and lakes become enriched with phosphorus. Streams respond quickly with higher production of diatoms but animal grazers keep biomass changes to a minimum. Fish productivity also increases. If phosphorus levels are too high, mosses become the dominant primary producer and sequester all of the nutrients. Growth of Arctic grayling under the present conditions only occurs in summers with higher than average stream flow. The present population would be stressed by warmer temperatures. When higher phosphorus levels reach lakes and cause slight eutrophication, the number of trophic levels will increase, especially within the microbial food web. Warmer lake temperatures increase stratification and, combined with eutrophication, could decrease oxygen in the hypolimnion. Oxygen levels will also decrease in winter under the ice cover. Eventually this habitat change will eliminate the lake trout, a top predator. Removal of lake trout results in a striking increase in abundance and productivity of smaller fish, including small lake trout, and the emergence of burbot as an alternate top predator. Large species of zooplankton will become virtually extinct.

J. E. Hobbie, B. J. Peterson, N. Bettez \& Linda Deegan, Marine Biological Laboratory, Woods Hole, MA 02543, USA; W. J. O'Brien, Dept. of Systematics and Ecology, University of Kansas, Lawrence, KS 66045, USA; G. W. Kling, Dept. of Biology, University of Michigan, Ann Arbor, MI 48109, USA; G. W. Kipphut, Murray State University, Murray, KY 42071, USA; W. B. Bowden, Landcare Research, P.O. Box 40, Lincoln, 8152 New Zealand; A. E. Hershey, Dept. of Biology, University of North Carolina-Greensboro, Greensboro, NC 27402, USA.

\section{Introduction}

Toolik Lake, on the North Slope of Alaska, is the site of a 25-year intensive study to predict the impacts of climate change on an Arctic aquatic system. The streams and lakes here are surrounded by tussock tundra. The study involves experiments in which nutrients, top predators, and permafrost depth are manipulated, and it includes mathematical models of biology and physics. Here we report predictions of impacts based only on those of our results that can be linked to the primary effect of future warmer temperatures, predicted by a variety of global climate models (e.g. Chapman
\& Walsh 1993). Other effects are possible and Rouse et al. (1997) stated that a decrease in run-off was also likely. However, this is controversial and it is generally thought that there will be an increase in Arctic precipitation with temperature warming.

\section{Research site and history}

The research site is the tundra, lakes and streams near Toolik Lake, Alaska $\left(68^{\circ} \mathrm{N}, 149^{\circ} \mathrm{W}\right)$, in the northern foothills of the Brooks Range and some $180 \mathrm{~km}$ south of the Arctic Ocean (Fig. 1). 


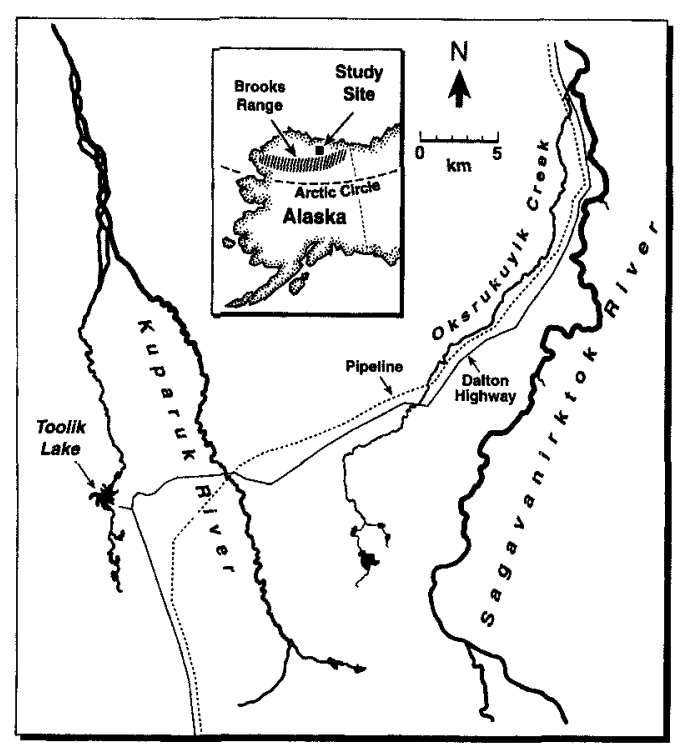

Fig. 1. Location of Toolik Lake in Arctic Alaska along the Trans-Alaska Pipeline. Redrawn from Deegan et al. (1999).

Temperatures average $-8.4^{\circ} \mathrm{C}$ annually while May through August temperatures average 0.6, $8.1,11.9$, and $7.4^{\circ} \mathrm{C}$. Low hills, formed by glaciers, are covered with sedges and grasses dominated by cotton grass mixed with dwarf birch, low willows and forbs. Soils are moist despite the low total precipitation of 200-300 mm. Streams and small lakes are abundant; the 4th order Kuparuk River and the $1.5 \mathrm{~km}^{2}$ Toolik Lake $\left(\mathrm{d}_{\max } 25 \mathrm{~m}\right)$ are the largest. The run-off season begins in late May, lakes thaw in mid to late June, and lakes and soils freeze in late September. Data are available at www.mbl.edu/html/ECOSYSTEMS/lterhtml/arc. html.

The history of Toolik Lake research and descriptions of the observations on lakes and streams are given by Hobbie (1997), O'Brien, Bahr et al. (1997), and Hershey, Bowden et al. (1997). The research has moved from (1) descriptions of the aquatic environment and the rates of ecological processes to (2) small-scale experimental studies of controls of productivity and of the abundance of plants and animals, and finally to (3) a series of long-term and large-scale experimental manipulations to examine controls of processes as well as responses of whole systems to changes that included additional nutrients in tundra, streams and lakes, increases in air temperature, and changes in the top predators of lake ecosystems.

In the following sections we report results of studies organized from primary to secondary effects of climate change. The only primary effect dealt with here is an increase in air temperatures. The secondary effects begin with physical-chemical effects of the thawing of permafrost, which lead to a release of phosphorus, and an increase in lake temperatures. Secondary effects continue with effects of added phosphorus on primary producers and effects of temperature and eutrophication on the top predators in lakes and on the stream fish.

\section{Primary effect}

Air temperatures will increase: For more than 30 years, the air temperatures in Arctic Alaska have been increasing. Data from Barrow, for example, show an increase of $0.7^{\circ} \mathrm{C}$ per decade. This is much more rapid an increase than predicted by global climate models and appears to be a regional phenomenon, rather than a whole-Arctic change (Chapman \& Walsh 1993).

\section{Secondary effects (physical-chemical)}

Permafrost thawing will increase phosphorus in streams: The permafrost in Arctic Alaska is warming but has not yet begun to thaw (Osterkamp 1994). Central Alaska, to the south, has had extensive thawing in recent years, with thermal erosion and slumping on hillsides. Near Toolik Lake, we were able to test the effect of thawing at a site where several metres of surface gravel were removed from glacial kames for road construction in the early 1970s. A stream that now passes through one of these disturbed kames is turbid and also is unusually high in phosphate and other nutrients; phosphate levels (soluble reactive phosphate) in this stream are more than twice as high as in any other stream sampled in this watershed $(n=23)$. In six years of summer sampling, this stream, called the MilkyWay, is nearly always higher in phosphate concentration than the larger stream (Toolik Inlet) into which it feeds (Fig. 2). We calculate that the MilkyWay contributes about $10 \%$ of the inflowing water to Toolik Lake but $30 \%$ of the phosphate and nitrate. 


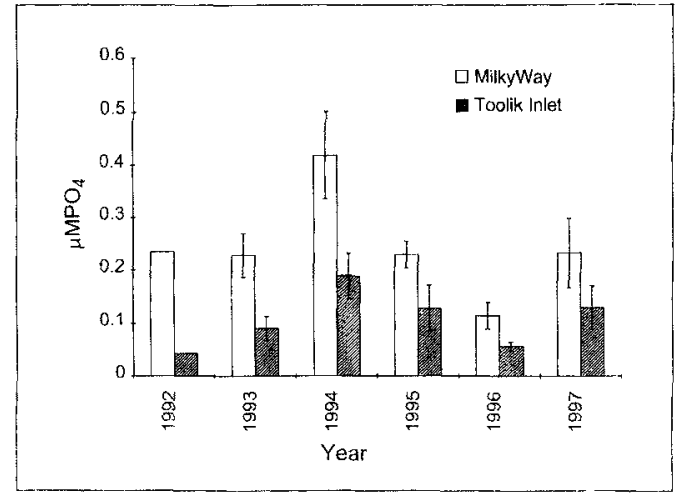

Fig. 2. Average summer concentrations of soluble reactive phosphorus in two streams of the Toolik Lake watershed. One stream, Toolik Inlet, was sampled where it entered Toolik Jake and the other (MilkyWay) at the point where it entered the Toolik Inlet stream. There was only one sample from 1992. The number of samples varied from 3 to 12 over the years; error bars indicate the standard error of the mean.

Our interpretation is that permafrost is melting and releasing stored nutrients.

Phosphorus input to lakes will increase but sediment chemistry reduces impacts: The effects of increased nutrient loading on Arctic lake ecosystems were studied in a long-term fertilization experiment in Lake N-2. The lake was divided with a polyethylene curtain, and the outflow half of the lake was fertilized for six years (1985-90) with inorganic nitrogen and phosphorus at a rate five times higher than the annual nutrient loading. As expected, phytoplankton productivity and biomass increased in response to the added nutrients. However, the rate of increase in primary production accelerated during the last year of fertilization.

The explanation for the acceleration lies in the interaction between phosphate and the very abundant iron in the sediments. This abundant iron, along with high concentrations of organic carbon and manganese, is characteristic of the sedimentary environments of Arctic Alaska (Kipphut 1988; Cornwell \& Kipphut 1992). Prentki et al. (1980) observed that phosphorus in shallow Arctic tundra ponds was strongly chemically bound to the abundant iron in the sediments. In Lake N-2 (Fig. 3), the added phosphorus became bound to the iron oxide layer for the first five years of fertilization and could not be recycled to overlying waters. By the last year of fertilization

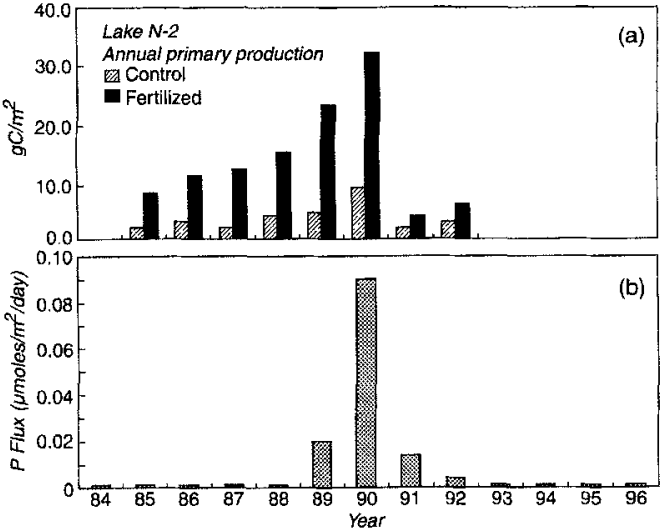

Fig. 3. (a) Primary productivity (annual) in the fertilized and control sides of the divided Lake N-2. Fertilizer was added from 1985 through 1990. (b) Phosphorus flux (average per day) from the sediments into the water of the fertilized side of Lake N-2.

(1990), the sedimentation of algae to the sediments had depleted the iron oxide layer because of iron sulfide formation, allowing large fluxes of phosphorus from the sediments. The rapid drop in phosphorus fluxes observed when fertilization ceased (1991) shows the importance of the unusual chemical nature of the Arctic sediments in sequestering nutrients (Sugai \& Kipphut 1992).

Lake temperatures will increase: The effects of a changing climate on the physics of Toolik Lake were predicted with the Arctic Lake Model (ALM), which simulates both physics and biology. The physical portion of the model has daily weather data as the only input and uses an eddy diffusion model similar to that of HendersonSellers $(1984,1986)$. For winter, the model uses an approach similar to Gu \& Stephan (1990) and includes heat storage in the sediment. From this, the ALM can simulate the annual thermal cycle of a lake (Fig. 4) as well as the annual oxygen depletion cycle during both summer and winter. Under a scenario of a $5^{\circ} \mathrm{C}$ air temperature increase, lake temperatures increased by ca. $3^{\circ}$ while the ice-free season increased by seven weeks.

\section{Higher order effects (biota)}

Primary producers in streams: As shown in the previous section, phosphorus will likely increase 
Toolik Lake temperature 1993-94

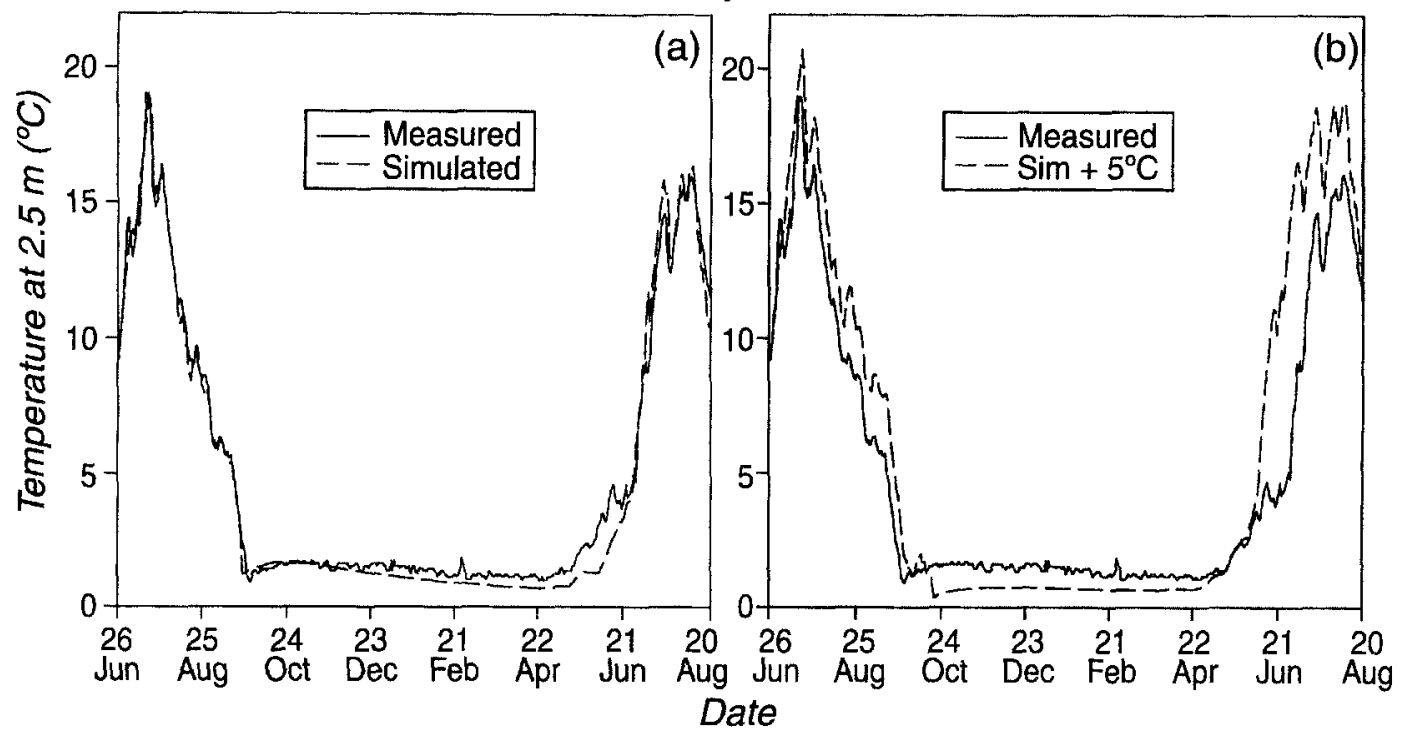

Fig. 4. (a) The output of the Arctic Lake Model for temperature in Toolik Lake compared with real data (measured) for a full year. (b) Real data (measured) for a single year in Toolik Lake compared with a simulation using a $5^{\circ} \mathrm{C}$ increase in air temperature.

in streams with warmer air temperatures. We investigated the biotic impacts of this increase with a manipulation experiment in the Kuparuk River, now in its 16th year of phosphorus fertilization (Fig. 5). The river ecosystem responds to $\mathbf{P}$ fertilization at the final concentration of only $1 \mu \mathrm{M}$ with increases in epilithic chlorophyll and primary production, increases in insect abundance in several taxa, and increases in fish production (Hershey, Hiltner et al. 1988; Bowden, Peterson et al. 1992; Deegan \& Peterson 1992). One remarkable finding is that the wide variation in discharge from year to year exerts even more powerful control over insect abundance and fish growth than the nutrient enrichment (Deegan \& Peterson 1992; Hershey, Merritt et al. 1995). However, some taxa do better at high flow and others at low flow conditions and thus the stream community overall benefits from year to year variability in discharge. A major reorganization of the stream community took place after 7 or 8 years of fertilization (Fig. 6) when a nutriophilic species of bryophyte, Hygrohypnum sp., began to proliferate on the river bottom (Bowden, Finlay et al. 1994). This moss now dominates primary production, controls insect habitat structure and hence species composition, traps tremendous quantities of fine particulates, and sloughs quan- tities of moss fragments and detritus during high discharge events. It may be having a negative impact on grayling production but more data are needed.

Primary producers in lakes: An increase of the fluxes of nutrients from the landscape into streams and then into lakes can clearly alter the structure and function of lake ecosystems. In the Toolik Lake region, eutrophication has been studied in limnocorrals, in a divided lake, and in a whole lake. The limnocorrals showed that these Arctic systems are potentially similar in response to temperate lakes; cyanobacteria bloomed (O'Brien, Hershey et al. 1992). The lake response ranged from a moderate increase in productivity in the divided lake (Fig. 3) to a cyanobacterial bloom in a whole lake. The differences were likely caused by different amounts of the iron oxide layer in the two systems.

Secondary producers: The secondary producers of lakes - zooplankton, insects and fish - are affected by changes in temperature as well as by the changes in oxygen brought about by eutrophication. One aspect of this is the effect on the habitat of the top predator, the lake trout. We have used the ALM model to simulate the effect of 
Fig. 5. The Kuparuk River data, 1983-1997. The temperature (bars) and discharge data (solid points connected by a line) are at the Dalton Highway crossing. The epilithic chlorophyll amounts, Baetis density, and adult grayling growth are seasonal means for a $2 \mathrm{~km}$ reach upstream (reference) and downstream (fertilized) trom the site where phosphorus was added continuously each summer.
Discharge \& temperature
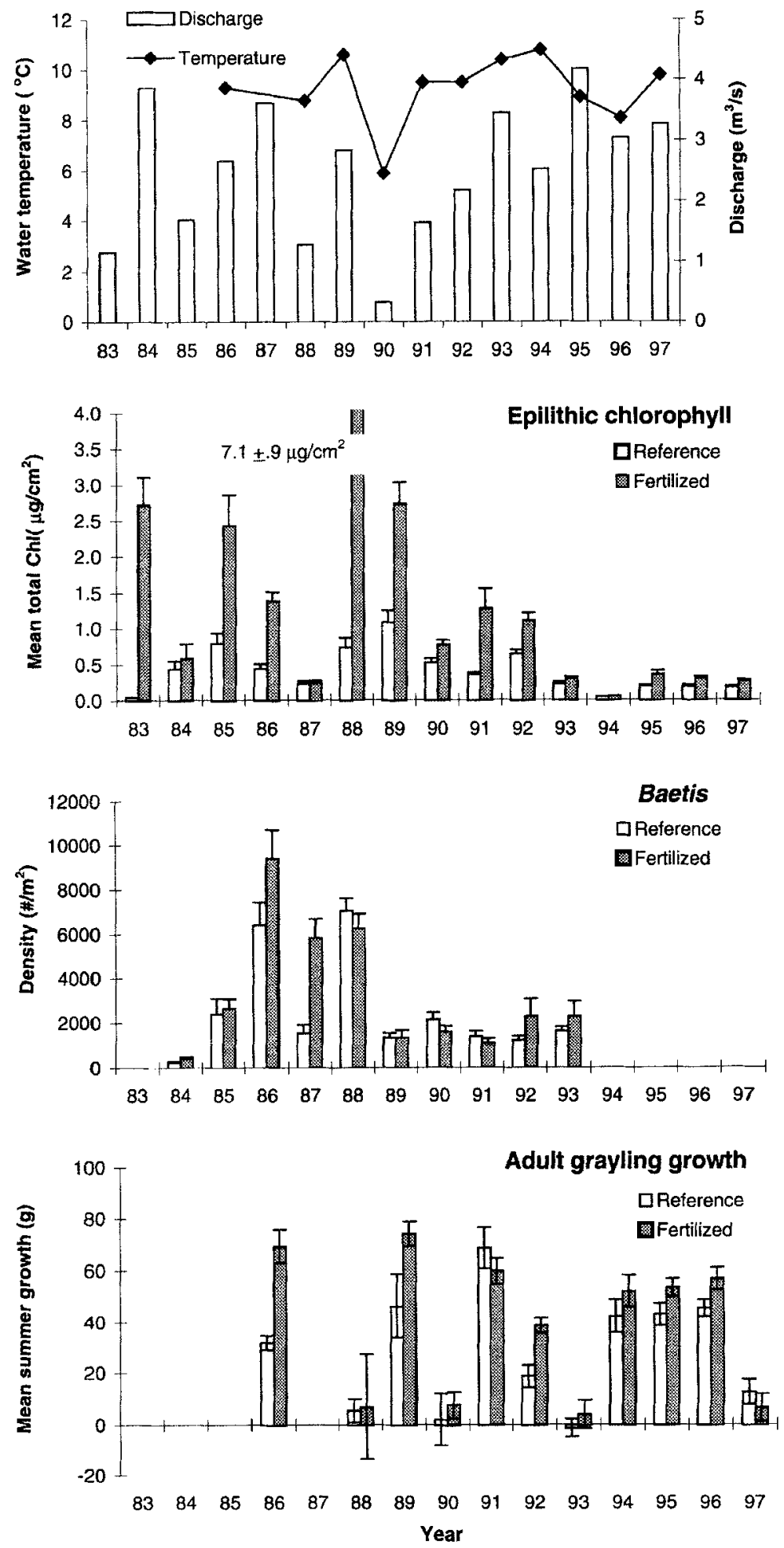


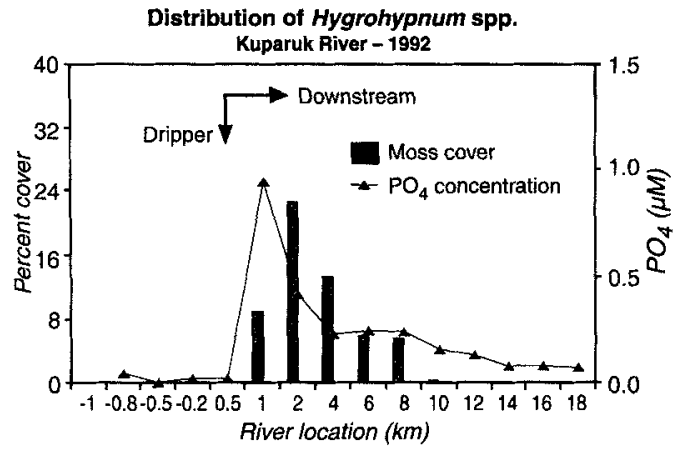

Fig. 6. The distribution of the phosphorus concentrations for one date in August 1992, and of the moss Hygrohypnum upstream and downstream of the phosphorus addition (dripper) in the Kuparuk River. The moss cover is the mean of 5 or 10 transects of at least 100 observations per transect. Data provided by W. B. Bowden.

increased nutrient loading and climate change on lakes of differing depths (Fig. 7). The depths where lake trout can thrive are indeed limited; climate warming of a few degrees will greatly reduce the habitat for these fish. The biological portion of the ALM model uses nutrient loading and sunlight intensity as inputs to simulate summer phytoplankton production and zooplank-

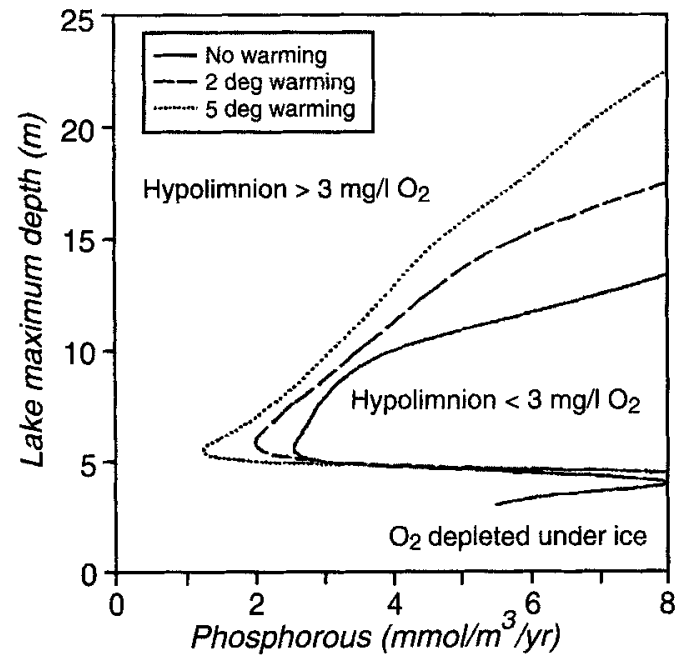

Fig. 7. Results from nuns of the Arctic Lake Model showing the critical combinations of the maximum depth of the lake and the phosphorus loading rate that produces a hypolimnion with less than $3 \mathrm{mg} \mathrm{O}_{2}$ liter $^{-1}$. This is the lower threshold for lake trout survival. The area of low oxygen increased with $2^{\circ}$ and $5^{\circ} \mathrm{C}$ increases in the climate.

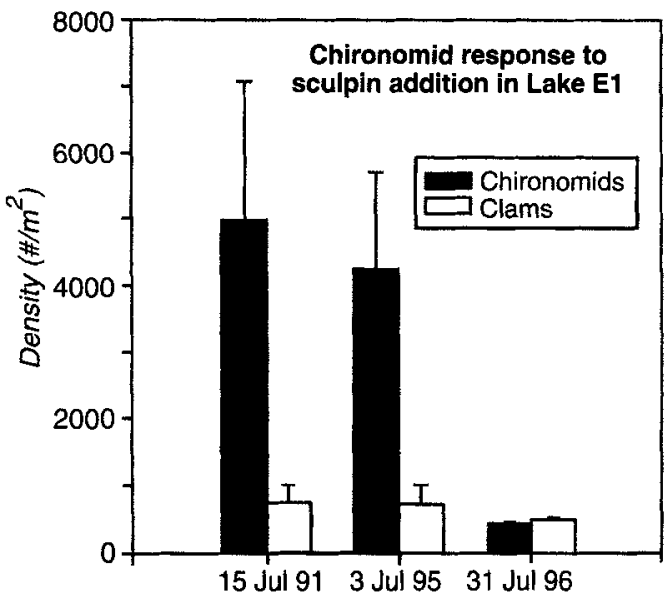

Fig. 8. Chironomid abundance in Lake E-1, near Toolik Lake, before and after sculpin addition to the lake in the summer of 1995. Data provided by A. E. Hershey.

ton biomass by integrating rate equations for nutrients, algae and zooplankton (Pascual 1994). The remaining phytoplankton is then transferred to deep water to induce summer and winter oxygen depletion.

When the lake trout are lost from these lakes in the future, what will be the biotic consequences? It is well known that in large lakes lake trout play a keystone role and control the size and density of fish and other animals in the lake food web. In Toolik Lake it appears that fishermen have removed the largest lake trout with a subsequent release from predation of smaller fish, such as grayling and young lake trout. As a result, the smaller fish have become abundant and eliminated the large zooplankton species (Hobbie et al. 1995).

Experimental manipulations have shown that lake trout predation also impacts the abundance of the snail Lymnaea (Merrick et al. 1992) and the density and habitat distribution of slimy sculpin (Hanson et al. 1991; McDonald \& Hershey 1992). When we tested our hypothesis about sculpin and removed all large lake trout from a lake, we were surprised to find that burbot, a minor part of the community, suddenly became very abundant. Instead of freeing the sculpin from predation, the experiment caused the emergence of another effective predator and so the sculpin became even more concentrated in the suboptimal rocky littoral habitat. Slimy sculpin are also effective predators of chironomids and when they themselves are free from predation they limit their prey to low 
densities in Toolik Lake (Cuker et al. 1992; Goyke \& Hershey 1992). This was shown dramatically in an experiment in which sculpin, newly introduced into a lake, drastically reduced the chironomid numbers (Fig. 8). We have recently added another predator, adult grayling, to a small fishless lake and found that they eliminated the very largest zooplankton but not the intermediate-sized zooplankton. Thus, elimination of lake trout by a climate change will have a variety of consequences as the impact cascades down the food web.

Nutrient increases in the future will have impacts that extend beyond the primary producers; this results from the control of food webs by the nutrients and primary production, the bottom-up control. In a limnocorral experiment we found added nitrogen and phosphorus greatly stimulated phytoplankton growth and, after a year's lag, zooplankton also responded with increased densities (O'Brien, Hershey et al. 1992). In an experiment in which nutrients were added to one side of a divided lake, the phytoplankton (Fig. 3) and most zooplankton species increased in abundance while Cyclops scutifer showed no response; this species is thought to feed on the microbial food web. Hershey (1990) found that the snail Lymnaea increased in abundance with added nutrients but chironomids, controlled by predaceous sculpin, did not.

Finally, there are also important impacts of a warming climate on the Arctic grayling, the single fish of streams near Toolik Lake. This impact was studied using a long-term record, extending over a decade, of changes in weight of individual grayling sampled at the beginning and the end of each summer in the Kuparuk River and Oksrukuyik Creek. Some summers were warmer than others and some had higher water discharge than others (Fig. 5) which allowed a stepwise regression analysis to be carried out (Deegan et al. 1999). For adult fish, $42 \%$ of the variance in growth rate could be accounted for by the combination of nutrient level, mean summer discharge, and consecutive days with extreme low flow. That is, grayling growth was reduced in years with low flows and high temperatures. This correlation between adult Arctic grayling growth rate and river discharge may be due to a balance between food availability and metabolic demands. High discharge sweeps benthic invertebrates into the drift, making them accessible as food for drift feeding fish, but the metabolic cost of swimming in the faster currents may be countered by increasing food intake, resulting in positive growth (Nielsen 1992). Conversely, low river discharge increases water temperature which also increases metabolic demands (Stolbov \& Alikin 1977) but at the same time drift is reduced and food is less. The combination of low river discharge and relatively high water temperatures can prevent the adult fish near Toolik Lake from gaining weight, or even cause them to lose weight (e.g. 1990, 1993, 1996). Given the complexity of the relationships among grayling growth, temperature and discharge, it is difficult to predict the effects of a warmer climate except to say that this particular population would find it difficult to survive. However, grayling are found throughout Alaska in stream waters much warmer than those near Toolik Lake so the potential for survival does exist in the species' genetic pool. We do not know if this population of fish will be able to adapt to the new climate regime.

\section{Conclusions}

Global change will likely cause a release of phosphorus from melting permafrost into streams and a change in the top predator of lakes caused by a shrinking habitat for lake trout. Streams and lakes will become more productive but the structure of the lake food web will change as the lake trout become extinct in this region.

Acknowledgements. - The research was funded by the National Science Foundation under the LTER and the Arctic Natural Sciences programmes.

\section{References}

Bowden, W. B., Peterson, B. J., Finlay, J. C. \& Tucker, J. 1992: Epilithic chlorophyll a, photosynthesis and respiration in control of a tundra stream. Hydrobiologia 240, 121-132.

Bowden, W. B., Finlay, J. C. \& Maloney, P. E. 1994: Long-term effects of $\mathrm{PO}_{4}$ fertilization on the distribution of bryophytes in an Arctic river. Freshwater Biol. 32, 445-454.

Chapman, W. L. \& Walsh, J. E. 1993: Recent variations of seaice and air temperatures in high latitudes. Bull. Am. Meteorol. Soc. 74, 33-47.

Cornwell, J. C. \& Kipphut, G. W. 1992: Biogeochemistry of manganese- and iron-rich sediments in Toolik Lake, Alaska. Hydrobiologia 240, 45-60. 
Cuker, B. E.. McDonald. M. E. \& Mozley, S. C. 1992: Influences of slimy sculpin (Cottus cognatus) predation on the rocky littoral invertebrate community of an Arctic lake. Hydrobiologia 240, 83-90.

Deegan, L. A. \& Peterson, B. J. 1992: Whole river fertilization stimulates fish production in an Arctic tundra river. Can. $J$. Fish. Aquat. Sci. 49, 1890-1901.

Deegan, L. A., Golden, H., Harvey, C. J. \& Peterson, B. J. 1999: The influence of environmental variability on the growth of age 0 and adult Arctic grayling. Trans. Am. Fish. Soc 128, 1163-1175.

Goyke, A. P. \& Hershey, A. E. 1992: Effects of fish predation on larval chironomid (Diptera: Chironomidae) communities in an Arctic ecosystem. Hydrobiologia 240, 203-211.

Gu, R., \& Stefan, H. G. 1990: Year-round temperature simulation of cold climate lakes. Cold Reg. Sci. Technol. $19,147-160$

Hanson, K. L., Hershey, A. E. \& McDonald, M. E. 1992: A comparison of slimy sculpin (Cottus cognatus) populations in Arctic lakes with and without piscivorous predators. $\mathrm{Hydro-}$ biologia 240, 189-202.

Henderson-Sellers, B. 1984: Engineering linnology. Boston: Pitman.

Henderson-Sellers, B. 1986: Calculating the surface energy balance for lake and reservoir modeling: a review. Rev. Geophys. 24, 625-649.

Hershey, A. E. 1990: Snail populations in Arctic lakes: competition mediated by predation. Oecologia 82, 26-32.

Hershey, A. E., Hiltner, A. L., Hullar, M. A. J., Miller, M. C.. Vestal, R. J., Lock. M. A., Rundle, S. \& Peterson, B. J. 1988: Nutrient influence on a stream grazer: Orthocladius microcommunities respond to nutrient input. Ecology 69, $1383-1392$.

Hershey, A. E., Merritt, R. W. \& Miller, M. C. 1995: Insect diversity, life history, and trophic dynamics in Arctic streams, with particular emphasis on blackflies (Diptera: Simuliidae). In F. S. Chapin III \& K. Koerner (eds.): The role of biodiversity in Arctic and alpine tundra ecosystems. Pp. 283-295. Berlin: Springer.

Hetshey, A. E., Bowden, W. B., Deegan, L. A., Hobbie, J. E., Peterson, B. J., Kipphut, G. W., Kling, G. W., Lock, M. A., Merritt, R. W., Miller, M. C., Rublee, P. \& Vestal, J. R. 1997: The Kuparuk River: a long-term study of biological and chemical processes in an Arctic river. In A. M. Milner \& M. W. Oswood (eds.): Freshwaters of Alaska: ecological syntheses. Pp. 107-120. New York: Springer.

Hobbie, J. E., Deegan, L. A., Peterson, B. J., Rastetter, E. B., Shaver, G. R., Kling, G. W., O'Brien, W. J., Chapin, F. S., Miller, M. C., Kipphut, G. W., Bowden, W. B., Hershey, A. E. \& McDonald, M. C. 1995: Long-term measurements at the Arctic LTER sites. In T. M. Powell \& J. H. Steele (eds.): Ecological time series. Pp. 397-409. New York: Chapman and Hall.
Hobbie. J. E. 1997: History of limnology in Alaska: expeditions and major projects. In A. M. Milner \& M. W. Oswood (eds.): Freshwaters of Alaska: ecological syntheses. Pp. 45-60. New York: Springer.

Kipphut, G. W. 1988: Sediments and organic carbon cycling in an Arctic lake. In E. T. Degens et al. (eds.): Transport of carbon and minerals in major world rivers, lakes, and estuaries. Part 5. Pp. 129-135. Hamburg: SCOPE/UNEP. (Also published in Sonderbd. 66 by Mitt. Geol.-Palaont. Inst., University of Hamburg.)

McDonald, M. E. \& Hershey, A. E. 1992: Shifts in abundance and growth of slimy sculpin in response to changes in the predator population in an Arctic Alaskan lake. Hydrobiologia 240, 219-224.

Merrick, G. W.. Hershey, A. E. \& McDonald, M. E. 1992: Salmonid diet and the size, distribution, and density of benthic invertebrates in an Arctic lake. Hydrobiologia 240, 225-234.

Nielsen, J. L. 1992: Microhabitat-specific foraging behavior, diet, and growth of juvenile coho salmon. Trans. Am. Fish. Soc. 121, 617-634.

O'Brien, W. J., Bahr, M., Hershey, A. E., Hobbie, J. E., Kipphut, G. W., Kling, G. W., Kling, H., McDonald, M., Miller, M. C., Rublee, P. \& Vestal, J. R. 1997: The limnology of Toolik Lake. In A. M. Milner \& M. W. Oswood (eds.): Freshwaters of Alaska: ecological syntheses. Pp. 61-106. New York: Springer.

O'Brien, W. J., Hershey, A., Hobbie, J., Hullar, M. A., Kipphut, G. W., Miller, M. C., Moller, B. \& Vestal, J. R. 1992: Control mechanisms of Arctic lake ecosystems: a limnocorral experiment. Hydrobiologia 240, 143-188.

Osterkamp, T. 1994: Evidence for warming and thawing of discontinuous permafrost in Alaska. Eos 75(44), 85.

Pascual, M. 1994: Periodic response to periodic forcing of the Droop equations for phytoplankton growth. J. Math. Biol. 32, 743-759.

Prentki, R. T., Miller, M. C., Barsdate, R. J., Alexander, V., Kelley, J. \& Coyne, P. 1980: Chemistry. In J. E. Hobbie (ed.): Limnology of tundra ponds. Pp. 76-178. Stroudsburg, PA (USA): Dowden, Hutchinson \& Ross.

Rouse, W. R., Douglas, M. V., Hecky, R. E., Hershey, A. E., Kling, G. W., Lesack, L., Marsh, P., McDonald, M., Nicholson, B. J.. Roulet, H. T. \& Smol, J. P. 1997: Effects of climate change on the freshwaters of Arctic and subarctic North America. Hydrol. Processes 11, 873-902.

Stolbov, A. Ya. \& Alikin, Yu. S. 1977: Temperature dependence of active metabolism and swimming speed of the Baikal Arctic grayling, Thymallus Arcticus baicalensis. (Engl. trans. Vopr. Ikhtiol.) J. Ichthyol. 17(1), 178-179.

Sugai, S. F. \& Kipphut, G. W. 1992: The influence of light and nutrient addition upon the sediment chemistry of iron in an Arctic lake. Hydrobiologia 240, 91-101. 